\title{
DIREITO DE AUTOR: NATUREZA JURÍDICA
}

MENDONÇA, João Josué Walmor de ${ }^{1}$

RESUMO: Esta pesquisa tem o objetivo de enquadrar o Direito de Autor quanto à sua natureza jurídica, baseado na estrutura teórica oferecida pelas doutrinas, ao longo do tempo, com a contribuição de sistematizar todas as teorias sobre o tema. Qual é o comportamento do conteúdo do Direito de Autor no direito de exclusivo, sem perder de vista a política adotada pelas teorias, descrevendo-as. Para isto, foi necessário balizar o presente estudo com a análise, tanto jusfilosófica, quanto dogmática, da doutrina, a legislação e jurisprudência. Na metodologia, utiliza-se dos processos de análise, sintética e analítica. Também, dialético, indutivo e dedutivo, quando a vertente e necessidade teórica e técnica se mostrar adequada. Espera-se que seja uma contribuição para o desenvolvimento científico.

Palavras-chave: Direito autoral. Natureza jurídica. Estrutura.

\section{COPYRIGHT: LEGAL NATURE}

SUMMARY: This source has the objective to fit the Copyright how much to its legal nature, based in the theoretical structure offered by the doctrines, to the long one of the time with contribution of systematic all theories about the theme. This is the behavior of the content of the Copyright in the right of exclusive, without losing of sight the politics adopted for the theories, describing them. For this, it was necessary to mark out with buoys the present study with the analysis, in such a way jusphilosophy, how much dogmatic, of the doctrine, the legislation and jurisprudence. In the methodology, it is used of the processes of analysis, synthetic and analytical. Also, dialectic, inductive and deductive, when the source and theoretical necessity and technique if show adequate. One expects that it is a contribution for the scientific development.

Keywords: Copyright. Legal nature. Structure.

\section{INTRODUÇÃO}

É necessário estabelecer a relação pertinente desenvolvida no presente trabalho com a realidade para determinar a importância da doutrina e sua estruturação ao longo da história na formação da legislação vigente. Portanto, uma abordagem histórico-filosófica.

Estratégica é a preferência ditada pela política do microssocial referente à matéria Direito de Autor porque converge aos lugares balizados em determinar qual será o conteúdo político na moldura da norma. Com o avanço tecnológico ficou patente a absorção da realidade frente ao normado, onde a atividade legiferante tem dificuldades em conter a produção normativa, a acentuar a inflação normativa, a gerar a incerteza, "[...] distancia-se de um dos eixos principais em torno do qual deve gravitar um Estado de direito: a segurança" (BARROSO, 2002, p. 47).

Esta consideração é irrestrita desta área objeto, visto a ganância em traduzir todos os fatos e engessar a sociedade com normas, a caracterizar a infidelidade natural responsável por unir os homens através da solidariedade; mas isto não resolve o problema das lacunas, no dizer de Bobbio (1999, p. 139140), estas são caracterizadas pelo seu conteúdo normativo injusto, propenso a não resolver as garantias positivadas.

\footnotetext{
${ }^{1}$ Pós-Graduado em Direito Público. Membro do Comitê de Ética em Pesquisa da FE/FFCL - CEP - (FE/FFCL). Coordenador da Comissão de Direitos e Prerrogativas dos Advogados da 70a Subsecção da OABSP, Ituverava-SP. Membro da Comissão de Ética e Disciplina, Secção de São Paulo, 70 ${ }^{a}$ Subseção, Ituverava-SP, participante como Instrutor. Advogado.
} 
A necessidade em tratar de um direito extremamente útil - sem a pretensão de ser apenas pragmático conforme se nota durante toda a história da humanidade -, chamado de Direito de Autor Droit D'Auteur. Adianta-se, em apertada síntese, os elementos responsáveis para a sua formação será a junção, a aceitação das teorias monista e dualista. Contudo, o Direito de Autor pode ser dividido em duas partes: parte moral e parte patrimonial. Essa dualista será, como tudo indica, a responsável última da finalidade existencial deste novo ramo do Direito.

A exposição de cada teoria doutrinária terá o condão de descrever quais os fatores, representados nos elementos informadores dessas teorias, pelos aspectos: a) moral ou pessoal; b) econômico ou patrimonial; e, $c$ ) intermediário, ou seja, dependendo da política legislativa de preferência no momento de preencher a moldura normativa com o conteúdo do objeto de proteção do bem jurídico almejado.

Assim, objetivo do presente trabalho é expor de forma sucinta, em uma linguagem acessível, o que vem a ser a estrutura e a natureza jurídica do Direito de Autor com a sistematização de todas as teorias sobre o tema. Na metodologia, utiliza-se dos processos de análise, sintética e analítica. Também, dialético, indutivo e dedutivo, quando a vertente e necessidade teórica e técnica se mostrar adequada. Necessita-se citar todos os nomes dos autores encontrados, tanto pela localização histórica pela importância e influência em cada vertente teórica.

Quanto ao estilo de exposição, sempre que houver citação e não indicar o autor remete-se a citação ao autor imediato que se cita no contexto, evitando o demasiado uso da citação autor-data, valendo-se de citação em nota de rodapé para explicar um termo ou apontar divergência doutrinária, quando pertinente.

\section{NATUREZA ESTRUTURAL}

Neste tópico, analisa-se a estrutura doutrinária informativa responsável pela formação científica do que vem a se conhecer por Direito de Autor - para o continente europeu - ou Direito de Cópia - para o sistema da common law (SILVA FILHO, 2002, p. 19).

A estrutura está dividida em doutrinas, separando-as em: a) monistas; b) dualistas; e, c) conciliatórias. Silva Filho (2002, p. 13) preferiu as dividir em: a) monistas; b) dualistas - ecléticas; e, c) monismo integral. Todavia, prefere-se a primeira separação, de Maria (1998, p. 7, v. 7), por estar bem estruturada e ser o norte e apoio desta pesquisa, principalmente neste tópico.

Ainda, enumera-se o desdobramento de Chaves (apud SILVA FILHO, 2002, p. 12), que remonta a classificação doutrinária em nove, a saber: a) Direito de Autor é um direito da coletividade, cita Manzini, quando o pensamento manifestado pertence a todos, a caracterizar "[...] uma propriedade social. A inspiração da alma humana não pode ser objeto de monopólio"; $b$ ) é um direito real de propriedade, sob fundamentação do trabalho; $c$ ) é uma emanação do direito da personalidade; $d$ ) é um direito especial de personalidade, e seu objeto tem um valor imaterial; e) é um direito sui generis, por não poder incluí-lo, segundo Picard, na divisão clássica tripartite do Direito Romano: direitos reais, pessoais e obrigacionais; $f$ ) direito de clientela: de Desbois, citada por Paul Roubier; $g$ ) direito dúplice de caráter real: pessoalpatrimonial; $h$ ) direito pessoal de crédito; e, $i$ ) direito privativo de aproveitamento.

\subsection{CLASSIFICAÇÕES DOUTRINÁRIAS}

\subsubsection{Doutrina monista e as cinco teorias}

Subdivide-se a teoria monista: a) privilégio (ou monopólio); b) realista da propriedade; c) negativista, também repartida em: obrigação ex-delicto e propriedade coletiva; d) personalista; e, e) 
patrimonial, em três posições diferentes.

\subsubsection{Teoria monista do privilégio}

Essa teoria monista do privilégio teve seu início no séc. XV e avançou até o séc. XVI, e surgiu com a idéia de Erasmo de Roterdã. Consistia na proteção da concessão a certos impressores o privilégio de publicações exclusivas de certas obras famosas (RIPERT, 2002, p. 375). Este Direito de Autor iniciou-se com os privilégios outorgados pelos monarcas, parlamentares, e logo em seguida pelas Universidades aos livreiros. Tal privilégio recaia sobre a própria produção intelectual, não recaia sobre a obra. Deste modo, o autor alienava toda a sua construção intelectual, a obra em si. A ratio desta época era a tutela da empresa e a miséria do autor, não a proteção da criação intelectual, mas a proteção dos investimentos (ASCENSÃO, 1997, p. 4). Diz Maria (1998, p. 8, v. 7), em referência ao autor, "[...] este deveria se contentar com a glória da recompensa moral, visto que as aviltadas retribuições econômicas apareciam como certos adiantamentos pecuniários dos editores, tachados estes por Fichte como ladrões privilegiados". Marion dizia ser um pacto social tácito entre o autor e a sociedade, e este asseguraria a aceitação e reprodução, aclamava Visconde de Carnaxide.

A evolução desta teoria tem seu fundamento na exclusividade, ou direito de exclusivo, como quer Ascensão (1997, p. 612, p. 4-5), que resultou no monopólio ou na exploração exclusiva. Nota-se que há a evolução da outorga daquele pacto social proposto por Marion para a outorga legal. Esta evolução relatada por Ascensão, para tutelar o autor, surgiu com o estatuto da rainha Ana, na Grã-Bretanha, em 1710, quando o autor apoderava-se do privilégio da indústria, no entanto, questiona se, ainda hoje, se não seria o inverso. Tal lei concebeu o privilégio de reprodução, na visão anglo-americana o copyright, materializando o exemplar e o direito exclusivo de reproduzir.

Os doutrinadores desta teoria são Renouard, Dupin, F. Ferrara, Randa Françon, Pilenko e Coelho Rodrigues. Entre os contemporâneos, Ascensão. Contribuíram para a sua elaboração Bedarride e Lajand. Maria (1998, p. 9, v. 7) diz que esta teoria está ultrapassada pelo simples fato de não existir, in case, pacto social tácito algum, também por afastar a realidade e ser uma "pseudoconvenção". Esta teoria tem marcadamente o elemento de direito pessoal. Pode-se utilizar o instituto do direito ao inédito, consubstanciado no direito de proceder ilimitadamente nas alterações na obra, bem como no de arrependimento com a retirada da obra da circulação. Contudo, um viés que poderá desmanchá-la será o acordo entre criador e editor, porque tal "negociabilidade" quebra a idéia de monopólio, pois nos monopólios é incabível conceber volição para sua utilização por outrem, in case.

\subsubsection{Teoria monista negativista}

Esta teoria de cunho negativista do direito pode ser subdividida em: a) obrigação ex-delicto, com Gerber; e, $b$ ) propriedade coletiva, com Manzini. A primeira tem o condão de explicar que o Direito de Autor surgiria em função de uma possível publicação da obra não autorizada pelo seu criador. Portanto, Maria (1998, p. 9, v.7) diz que inexistindo o delito, a violação do Direito de Autor não efetivaria ou aplicaria este direito. Assim, como justifica-lo? Caso não ocorra o delito, como haverá qualquer tipo de direito, ou qualquer tipo de participação econômico do autor? Contudo, é patente a obrigação de reparar frente a uma violação aos direitos de outrem tendo em vista a coerção do Direito. Assim, não se sustentou a teoria de posição negativista de cunho ex-delicto.

A teoria negativista da propriedade coletiva tem nome de maior expressão em Manzini. Tal teoria recusou qualquer direito real, especialmente o patrimonial privativo do autor, não existindo qualquer obrigação e direito real exclusivo do autor. Até o pensamento pertence à coletividade, como diz Deboor 
(apud MARIA, 1998, p. 10, v. 7), em seu Droit D’Auteur, que as obras do espírito não são propriedades dos autores, a justificar que o destino pertenceria ao povo, pois, se o ser humano, tocado pela graça e realizando atos de criador, tal privilegiado não teria podido realizar sua obra se não fosse alimentado pelo tesouro representando a cultura nacional. Assim, como pertenceria a todos, ela serviria para atender o bem-estar dos povos, por isso dizia ser uma propriedade social. Uma vez que a obra seria fruto do meio e o criador utilizaria deste meio para produzir sua criação. E, neste sentido, Boileau e Macaulay mencionavam que o autor deveria se contentar com os louros da sua criação.

A justificação em Maria (1998, p. 10-1, v. 7) de que não haveria um todo errôneo, porque na sua parte procedente, dever-se-ia assegurar os Direitos do Autor na órbita jurídica e não somente na ordem moral, pois, haveria um interesse econômico-pecuniário do autor, como também haveria aquele interesse em toda ordem social-econômica capitalista, pugnando, assim, a coexistência desses interesses. Chaves (apud MARIA, 1998, p. 10-1, v. 7) cita o caso da antiga URSS no momento da instauração da coletividade integral, que se estabeleceu ao Estado ser devido o Direito de Autor, e o autor surgindo como simples e exclusivo assalariado, "um trabalhador intelectual". Ainda Maria, consideraria o direito pessoal de autoria o plus do direito autoral, seria incabível a expropriação da obra intelectual: porque pela sua própria existência, estaria sempre a servir a comunidade.

Toffat (MARIA, 1998, p. 11, v. 7), séc. XIX, dizia que o exacerbado individualismo voluntarista fomentaria a riqueza de poucos com a diminuição da liberdade. Contudo, eclodiu a Revolução Burguesa e com ela a proprietarização do direito autoral. Laboulaye leciona no sentido de "[...] falai de propriedade, todos se inclinam, falai de privilégio, todos se revoltam. O primeiro título representa o que há de mais respeitável: o direito; o segundo o que há de mais odioso: o monopólio". Mas, não se deveria esquecer que o Direito de Autor seria fruto do labor humano, consistente em bens tangíveis, arte e engenho, mas também se poderia contrariar Ihering, em referência a Ferrara, momento em que diz haver um nivelamento jurídico dos bens materiais e imateriais porque estaria presente no social e, portanto, deveria estar também no direito. Em França, houve o nivelamento do Direito de Autor ao domínio comum. Contra: Chapelier, Lamartine e Lakanal. A favor: Luiz Napoleão. Os primeiros por consideravam ser sagrado e imanente à própria existência do indivíduo, como direitos do gênio. O segundo, a obra intelectual gozaria das mesmas vantagens que uma casa.

\subsubsection{Teoria monista realista da propriedade}

Após esta passagem da Revolução Burguesa, surgiu o liberalismo voluntarista do séc. XX, chamada de doutrina realista. São seus autores: Fichte, Hegel, Diderot, Lamartine, Ihering, Ahrens, os Terrieth, Filomusi Guelfi, Hoffmann-Klöstermann e Dias Ferreira. No direito clássico galego: Chironi, Laboulaye e Pouillet (MARIA, 1998, p. 12, v. 7).

Característica marcante desta teoria, o nivelamento do direito de autoria - tido como propriedade intelectual, literária ou artística - ao nível da propriedade comum. Alerta-se que este nivelamento causou conflitos relativos à essência do que vem a ser os princípios do direito dominial comum, também quanto a sua aplicabilidade ser incompatível à configuração dos direitos pessoais de autoria. Neste diapasão, Desbois (apud MARIA, 1998, p. 12, v. 7) ressalva que a discricionariedade que a exclusividade comportaria seria de outra essência que o absolutismo da propriedade, pois, se o autor teria o abusus e o frutus, não reuniria o usus.

Outra característica marcante seria a possibilidade de haver abuso antes da publicação, que se relacionaria ao direito de inédito. Sobre este direito, Leite (2004, p. 115) cita o caso Donaldson V. Becket, que em 1774, a House of Lords Inglesa julgou, a considerar o Ato da rainha Ana, decidiu-se que o autor de

Nucleus, v.9, n.1, abr.2012 
um livro ou composição literária teria o direito exclusivo de autorizar a primeira publicação/impressão, acionando a primeira pessoa que imprimisse, publicasse ou comercializasse a obra sem o seu consentimento.

Para esclarecer e separar esta dicotomia ventilada pelos teóricos desta corrente, Caselli e Stolfi (apud MARIA, 1998, p. 12, v. 7), nomeia algumas considerações entre o direito dominial comum, sendo: a) diversos modos de aquisição originária e derivada; $b$ ) inaplicabilidade de regras de condomínio na comunhão autoral; c) distinta duração dos oito direitos, v. g., perpetuidade, transitoriedade; d) imprescritibilidade de um não ocorrente com o outro, a diversificar os efeitos da posse; e, e) diferenciado tratamento protetor com ações específicas, em especial o direito moral do autor.

Críticas a esta teoria de cunho realista, iniciada na Alemanha, com Gierke. Logo surgiria também em Kant, aquele dizia ser (apud MARIA, 1998, p. 13, v. 7) no individualismo a maior dignificação e exaltação da personalidade não estaria em atribuir a uma res, mas na identificação da obra (criatura) com o escritor (criador), dentro de uma visão indefinida.

Tolstoi e Herculano se declarariam no sentido de que é a manifestação da liberdade, a projeção da pessoa humana. Bertrand diz que o Direito de Autor é um ius personalissimum. Bluntschili embala na assertiva deste e sagra com um direito natural do homem², suplica a emanação de sua própria personalidade. Tais idéias influenciariam Pouillet (MARIA, 1998, p. 13, v. 7), "[...] que reconhecendo a preponderância do sentido pessoal após a revisão feita por Maillard não desprezou, contudo o componente econômico". Este posicionamento foi decisivo para Gierke reestruturar esta teoria, para calcá-la em termos dualistas, com a prevalência do lado pessoal.

\subsubsection{Teoria monista personalista}

Em contrapartida, também na Alemanha, insurge postulações de Köhler com notável polêmica ao já mencionado pensamento de Gierke. Esta nova abordagem requeria o chamamento de personalismo mitigado, onde o elemento econômico teria uma posição menor. Malaplate (apud MARIA, 1998, p. 11, v. 7) salienta que este elemento não seria constitutivo, mas seria um efeito do exercício do próprio direito pessoal, informando uma ideia de personalidade que interviria no domínio de direito do autor, mesmo que não pareceria tratar de questões pecuniárias, e apresenta questionamento: "Não deve a natureza jurídica dum direito ser procurado justamente no que constitui a sua essência?" Este postulado arrebataria os seguintes juristas: Dahn, Heymann, Malaplate, Marwitz e Tobias Barreto.

\subsubsection{Teoria monista patrimonial mitigada}

Com a falência destes empreendimentos teóricos acima, surgiria a teoria mitigada ou a teoria patrimonial mitigada. Haveria nesta teoria três divisões: a) teoria da quase propriedade, proposta por De Giudice; $b$ ) teoria do direito real e do usufruto, de Otto Lenghi e Maraglia; e, $c$ ) teoria da propriedade limitada ou sui generis, com Vidari, Astuni e Gianturco.

Assim, a consideração da característica sui generis da propriedade que Giarturco a conceberia como um regime jurídico específico e autônomo, ou seja, diferentemente da acepção comum do que seria a propriedade (nos moldes do direito real). Ademais, o resultado da complexidade dessa autonomia enquadraria tal qualificação fora da identificação com a propriedade comum - a saber, vale a distinção da

\footnotetext{
${ }^{2}$ Para um futuro e aprofundado estudo sobre a concepção de Direito Natural ser ou não uma manifestação da emanação da própria personalidade humana ou o modo-de-ser próprio do ser humano, a não invocar a subjetividade aristotélica. Percebe-se que tais atribuições de Bertrand possam fazer valer o Direito Natural da fase formulada pelo holandês Hugo Grotius, que é a fase iluminista da idéia de Direito Natural. Tal mudança de eixo é que este Direito não se referiria à natureza das coisas, mas à natureza humana: a própria natureza humana seria a mãe do Direito. Cf.: Araújo (1988, p. 14), Martins Filho (1992, p. 56).
} 
propriedade estrita, tratada pelo direito real, propriamente dito. Mas, para Vidari, que se apega com a qualidade de propriedade especial, que correria a sua limitação pelo fator tempo ${ }^{3}$. Com essa limitação, indicaria a propriedade como resolúvel, a colocar o Estado no senhorio direto, após a morte do autor. O que possibilitaria a conclusão que os herdeiros seriam desconsiderados.

A justificativa para esta teoria é insatisfatória no dizer de Maria (1998, p. 14, v. 7), "porque o caráter sui generis, a conduziria em outro rumo na direção da posição conciliadora dos direitos individuais de Picard".

Também, outro fator limitador, seria o direito real de usufruto de Otto Lenghi. Neste diapasão de argumentos, Orlando Gomes (apud MARIA, 1998, p. 14-15, v. 7) ventila que dogmaticamente tal explicação careceria de valor, pois seria recurso tendente a acomodar ideia preconcebida, pois, justificaria que se de propriedade se trataria, não deveria reclamar estatuto que contrariasse pontualmente o domínio, mas, do ponto prático, a teoria da propriedade sui generis favoreceria a sistematização da matéria nos códigos, como em algumas legislações, proporcionando o acentuado aspecto patrimonial dos direitos de autor, facilitando a regulamentação. Deste modo, Orlando Gomes, com maestria notável, fornece motivos a contribuir no posicionamento do legislador ${ }^{4-5}$.

\subsubsection{Doutrina dualista e as duas teorias principais}

Neste diapasão dualista-eclético, analisar-se as proposições de Köhler, notadamente com a natureza distinta da propriedade autoral, que recairia sobre bens imateriais ou espirituais. Foi revolucionária, mesmo antes de se fixar como uma doutrina dualista - geistiges eigentum. Hubmann frisa que seria uma posição mista, com elementos personalista e propriedade comum, e que afastaria dela todas as críticas possíveis. Sobre a idéia da natureza específica do seu objeto, doutrinaria Köhler (MARIA, 1998 , p. 15, v. 7) que em um valor imaterial e não no objeto que lhe serviria de suporte, pugnando pela idoneidade para distinguir tal direito de um vulgar direito de propriedade, pois teria em comum com ele a noção de um direito sobre um bem, permitindo a compreensão do caráter absoluto e temporário das prerrogativas sobre ele destinadas ao autor. Tais caracteres seriam imateriais, incorpóreos, mas caráter de realidade, portanto, seriam tão reais como as forças que animariam a natureza e a vida.

Houve o duelo entre Köhler e Gierke, ressalta Philadelpho Azevedo, que para Gierke (apud MARIA, 1998, p. 15, v. 7) vocalizava o bem jurídico fora do direito do autor, mas nele próprio, confundindo a única essência, incindivelmente, entre criador e a criatura. Köhler diria que a distinção entre a íntima atividade pensando do homem e a entidade externa do pensamento externado excluiria a teoria da personalidade, "[...] mesmo a propriedade material será mesclada de elementos individuais e não poderia sequer ser construída sem uma parcela concorrente de direitos pessoais".

Mas, conforme citação supra, Blasi, Garcia e Mendes, apud Mileo e Soares, os bens corpóreos nas manifestações intelectuais não seriam aplicados.

Destes aportes críticos e conflitantes, surgiram as teorias de Köhler a frente - dualista personalismo mitigado de Berard, Palmard e Stolfi -; e, a teoria de Gierke, a patrimonial da clientela de Paul Roubier (1963, p. 374).

\footnotetext{
${ }^{3}$ Divergente a este posicionamento, conferir nota anterior de que igual pensamento coaduna-se. O elemento temporal será regido pela teoria do direito real, bens materiais, a desprezar os elementos da teoria dos direitos intelectuais, bens imateriais.

${ }^{4}$ Em que pese o argumento de autoridade de Orlando Gomes, sistematicamente refuta-se a preferência por acentuar o conteúdo patrimonial. Antes disso, propõe-se a equivalência entre o aspecto moral e o pecuniário, quando, o que se nota do texto citado, a preferência pela parte capitalista do Droit D'Auteur.

Mileo e Soares (2005, p. 64), os autores citam Blasi, Garcia e Mendes: “As regras referentes à propriedade intelectual não podem ser aplicáveis às coisas corpóreas, tendo em vista as divergências entre os bens imateriais e os bens materiais, principalmente no que concerne a ubiqüidade, ou a onipresença, do bem imaterial".
}

Nucleus, v.9, n.1, abr.2012 


\subsubsection{Teoria dualista da prevalência realista}

Tais comentários surgiram após a Conferência de Berlim, acolhendo a concorrente integração do elemento pessoal, assim, ao lado do Droit D'Auteur, como um direito sobre um bem imaterial. Desta forma, existiria um direito de personalidade e que o aspecto patrimonial dificilmente se enquadraria nos quadros do direito da personalidade - Persönlichkeitrecht. Como fazer tal distinção? Köhler, aparentemente, com seu elemento patrimonial dizia ser essencial para esta distinção da propriedade material, quando relacionada ao domínio comum sobre bens corpóreos, tratado assim por Philadelpho Azevedo (apud MARIA, 1998, p. 16, v. 7).

Caselli, a comentar Köhler, dizia que este não poderia refutar as duas prerrogativas: $a$ ) as de caráter pessoal fora do Direito de Autor, em pertinência ao domínio da genérica proteção da personalidade; e, $b$ ) o mero paralelismo com as faculdades patrimoniais, que constituiriam todo aquele direito.

Dizia ainda Stolfi, que nestas prerrogativas residiriam as principais anomalias da sua teoria, já Gierke preferiria dizer que o erro estaria em carecer de sustentação da base legal (apud MARIA, 1998, p. 11, v. 7). Tal teoria tinha os seguintes juristas: Stobbe, Perrau, Beseler, Prager, Maillard, Ferrara, Lauterbach, Sacerdolli, Werner. Ainda, em França, poder-se-ia assumir três perspectivas: $a$ ) ora vertendo em Picard, com Plaisant, Jean Rault, George Bry; $b$ ) ora em Berard, da propriedade, com Perrau, D’Argoeuves, Newstetel-Wener, Lauterbach e Maillard; e, c) o próprio Köhler.

\subsubsection{Teoria dualista da prevalência personalista (mitigada)}

A controvérsia: Köhler vs Berard, Marillot e Palmard. O primeiro com a sua teoria eclética prevalente; os segundos, com a prevalência do elemento pessoal (moral), e que poderia ser considerada a segunda teoria, sendo chamada de teoria da prevalência personalista. Esta teoria merece atenção redobrada, pois o elemento personalista está em vantagem sobre o elemento (ou caráter) da propriedade limitada e especial, notados por Gierke e Geny. Defendem esta posição Marillot - como primeiro idealizador -, mas outros autores atribuem-na a Berard, tais como Geny, Stolfi, Palmard, Argoeuves, Luchaire, Zool e Boor.

Uma distinção para elucidar o conflito com a teoria de Köhler e Berard, enquanto o primeiro preferiria a proteção pecuniária ao direito de personalidade, o segundo preferiria o direito pessoal, extrapecuniário, ao pecuniário. Philadelpho Azevedo (apud MARIA, 1998, p. 17, v. 7), lecionaria que "[...] uns, mais espirituais, dão preferência ao pessoal, outros, mais práticos, ao pecuniário; ninguém mais pretende a exclusividade de quaisquer deles, girando a discussão em torno da simples gradação".

\subsubsection{Doutrina conciliatória ou conciliadora e as três teorias}

A doutrina conciliatória parte-se em três, muitas das vezes, a confundir o cientista quando se anunciar, novamente, alguns elementos de teorias já vistas, pois o desenvolvimento desta doutrina tem-se nas teorias que, diga-se, moldam os referidos elementos, necessitando, portanto, apresentar o fluxo desses moldes evolucionistas. O mesmo para os autores e as suas respectivas teorias. Isto porque esta teoria é a fusão de elementos, justaposições: com ênfase nos direitos intelectuais, direitos específicos, ou direito dúplice ou complexo.

\subsubsection{Teoria conciliatória monista dos direitos intelectuais}

Esta vertente doutrinária surtiria grande impacto na legislação mundial, notadamente na Lei belga 
de 1886. Acordaram a esta teoria, um rol de juristas, tais como Henri Capitant, Ambroise Colin, De Borghaeve, Escarra, Hepp, Gareis, Orelli, Jean Reault, Ortoff, Weis, Plaisant e George Bry.

Picard diria ser um monismo moderado de dupla face, mas alterada por um de seus seguidores, no seu aspecto moral. Com esta elasticidade, dificultaria a determinação do seu conteúdo. Paul Roubier criticaria Picard, pois seu conteúdo nada dizia, opondo-se aos direitos reais e de crédito, do primeiro. Capitant et Colin (apud MARIA, 1998, p. 18-19, v. 7) seguiriam com extremo, enquadrariam nesta categoria, como intelectuais, tais como: a) o direito do médico sobre seu consultório; $b$ ) direito dos agentes de seguro, sobre seu escritório profissional ${ }^{6}$. Assim, mais críticas, além das de Roubier, agora de Henri Desbois, a fundamentar que seria incorreta a diferença entre a escolha de uma marca de conteúdo destinada a atingir e reter a clientela e a criação de uma obra suscetível de desempenhar uma atração literária (finalidades diferentes), pois tal extensão mais confundiria que esclareceria os traços do próprio autor.

Lecionaria Orlando Gomes que seria irrealizável a fusão desses direitos, porque seria a criação de nova entidade. Verificando-se que seria a justaposição de um ou outro elemento, conforme sua preferência ou incidência de sua manifestação positivada. Dependeria de como se encararia a obra, e também de como se manifestaria a personalidade do autor. Seria o caráter político de aplicação mediante a legislação, devendo-se notar a legislação autoral. Continua Orlando Gomes, a citar Sanctis (apud MARIA, 1998, p. 19, v. 7), posicionando-se: o reflexo como referência entre a coisa e a pessoa ao mesmo tempo, “[...] e que tornaria gravemente incertas a vontade e a importância do comando legislativo e a interpretação das várias disposições legais". Mas, Stolfi censurando o posicionamento de Desbois, dizia que este monismo do direito de dupla face seria um Janus jurídico, complementando, a saber, que "[...] le droit ne connait aucun de ces monistres bicephalos dout la science ne peut retirer aucun avantage".

Ao lado desta teoria, surgiria a variante patrimonial da clientela com uma solução conciliadora dualista de Desbois, também citada por Paul Roubier.

\subsubsection{Teoria conciliatória neodualista ou do direito dúplice e complexo}

Aqui se encontra um monismo mais temperado ou bilateral, qualificado como neodualismo. Duval, a citar Picard, dizia que muito contribuiu com ela porque um direito com natureza dúplice, a basear seus elementos característicos constitutivos, ou seja, o moral e o pecuniário (apud MARIA, 1998, p. 19, v. $7)^{7}$.

\subsubsection{Teoria conciliatória dos direitos específicos ou sui generis}

Esta teoria foi desenvolvida por Piola Caselli, partindo de Picard, é a teoria mais nova e apurada da concepção de direito sui generis intelectual.

Têm as seguintes características: a) um monismo formal (legal) e prático; b) dentro da classificação tripartite romana - direito pessoal, direito real e direito obrigacional; e, $c$ ) coloca outra categoria para o seu direito misto e híbrido, ao lado da dicotomia real-pessoal: a real típica dos bens materiais que integra o patrimônio (parte-se da ideia primitiva de Köhler).

\footnotetext{
${ }^{6}$ Em Ripert (2002, p. 375-6): "No exercício das profissões civis, manifesta-se igualmente o desejo de poder ceder a clientela constituída. Algumas dessas profissões exigem hoje instalação, aperfeiçoada e aparelhagem custosa. O material tem quase tanta importância quanto o valor do prático. Este, alias, de bom grado procura preservar-se contra a concorrência, e não ficaria zangado se se lhe atribuísse um cartório". Segue o autor em nota explicativa n. 44: "Uma ordenança de 18 de julho de 1945, expedida em proveito de médicos, cirurgiões-dentistas e parteiras, prisioneiros, deportados, requisitados ou mobilizados, permite criar em torno do seu gabinete uma circunscrição reservada num raio de 20 quilômetros no máximo, no qual nenhum novo facultativo poderá instalar-se, salvo a título de substituto de um prático em exercício".

${ }^{7} \mathrm{O}$ autor não se estendeu a respeito desta vertente. Não se encontrou nenhum autor que pudesse esclarecer tal teoria. Nucleus, v.9, n.1, abr.2012
} 
Diz Maria (1998, p. 20, v. 7) que o fundamento consolidado dos defensores desta corrente, para estabelecer tal posicionamento, estribar-se-ia que: a) não se cogita a equivalência entre as faculdades pessoais e reais, pois elas se interpenetram, são contínuas; e, $b$ ) a tentativa de conciliar as posições de Köhler e Gierke.

Com Köhler, ter-se-ia o direito moral com maior amplitude, ao passo que em Gierke o direito de propriedade imaterial receberia maior amplitude, o que formaria a teoria da personalidade pensante de Piola Caselli. Então, a estrutura desta teoria passaria a ter o lado pessoal (paternidade intelectual) e o lado patrimonial econômico.

A justificativa seria a união dos dois postulados - formula-se, assim, a possível solução: Köhler + Gierke $=$ Caselli - favorecendo a normatização e a aplicação na realidade. Com isto, apareceriam tais ordens distintas - direito moral prevalecendo e direito de propriedade imaterial prevalecendo - reguladas por um único regime legal. Assim, justifica-se o nome dualismo, ao lado de um monismo formal.

Em Picard, direito coletivo e sui generis, as faculdades pessoais e reais seriam colocadas ao mesmo nível. Com Caselli, dentro do direito subjetivo especial de notória complexidade: as faculdades com preponderância e um relevo maior sobre o elemento moral, favoreceria sempre um direito moral do autor.

Com isto, este posicionamento se pacificaria na doutrina o elemento moral e nos regimes legais, afastando-se de Köhler (dualismo formal), desta forma. Caselli apoiou-se em Alfred Mitteis, Ulmer, Hubmann, Dumbach, Riezler, Röthliberger, Gregório e Giorgio Giorgio (apud MARIA, 1998, p. 20, v. 7). Tal posição surgiria do novo monismo vs o dualismo pendular de Köhler e Gierke (de prevalência personalista).

Daí que Maria (1998, p. 21, v. 7) levantaria propostas questionadoras, a saber, se: a) o direito pessoal (moral - extrapecuniário) do autor e o real coexistem independentes, dentro de regimes legais autônomos e específicos ou seria um único, embora com natureza pública, sob mesma regência legal? e, $b$ ) estariam nivelados, em pé de igualdade, ou algum deles sobrepujaria ao outro dentro das concepções monistas?

Almeida Santos entenderia ser uma disputa válida, Philadelpho Azevedo admitira os dois aspectos, sendo eles prevalecentes em momentos distintos, pois possuem características divergentes, distintas que podem ser fundidos em uma síntese natural (apud MARIA, 1998, p. 21, v. 7).

Estas propostas, unidas à de Zool e Caselli, constituem a problemática atual. O primeiro proporia a dissociação dos elementos, e o segundo, reivindicaria a unidade, como quer Maria (1998, p. 21, v. 7). Ascensão (1997, p. 582), pugnaria por não encontrar um caráter unitário, apesar deste direito partir de um feixe de direitos e faculdades ${ }^{8}$. Maria (1998, p. 22, v. 7) diria que “[...] a esmagadora maioria dos juristas propugna pela unidade formal (legislativa) do direito de autoria, contida num único estatuto legal”. Assim, Piola Caselli (apud MARIA, 1998, p. 22, v. 7) ventila:

[...] o instituto jurídico nasce da criação da obra é real e eficiente desde o momento da criação, tendo um sujeito determinado: o autor; um objeto próprio e determinado: a obra citada; uma própria e especial causa jurídica: o fato da criação; finalmente, um próprio e especial regulamento jurídico.

Continua o autor a dizer que tal concepção seria romper com a unidade do novo instituto, e, portanto, uma aberração. Então, insiste, apontando justificativa de diferença na abordagem e na utilização metodológica:

\footnotetext{
${ }^{8} \mathrm{O}$ autor se apóia na receptação na lei: "Mais do que a execução coerente duma concepção de base, [...] se misturam princípios de proveniências diversas, em vez de se reduzirem a um sistema unitário."
} 
[...] o excessivo subjetivismo analítico do espírito alemão, contra o qual deve reagir o espírito sintético latino. $\mathrm{O}$ direito de autor é único, tanto o anterior à publicação da obra, como direito de inédito, como o posterior a ela, tanto o que respeita às faculdades de ordem patrimonial, como o que tutela a personalidade do autor.

Por outro lado, observar-se-á, que a unidade formal, em termos legislativos, pode ser rompida na práxis. Assim, há necessidade de dizer que muitas das soluções apresentadas ao tecnicismo-positivo do modelo burocrático-positivo, tende a buscar soluções extra-ordenamento, ou seja, a sanar as lacunas injustas impositivas próprias deste ordenamento burocrático-positivo.

\section{NATUREZA JURÍDICA}

\subsection{PRELIMINARES AO TEMA}

A consideração de ordem estrutural implica na finalidade de mirar e focalizar o problema localizado na estrutura e da natureza do direito. As teorias responsáveis em dar suporte ao conhecimento do legislador e, desta forma, informações doutrinárias e teóricas para preencher a moldura ${ }^{9}$ normativa, aparece-se aqui, com a eleição de uma teoria. A demonstração que a ciência, no dizer de Correas (1995, p. 95), tem um discurso igual aos outros, com a pretensão de ser descritivo, a forçar seu autor seguir regras estabelecidas pelo discurso: método científico.

Esclarece que este discurso, tal qual a filosofia moderna deveria ser contrastados com outro de caráter de "comprovações empíricas". E, no entanto, como todo discurso científico seria político, diz, ainda mais em tratando de ciências sociais, a ciência dependeria da teoria que fundamenta, questionando: "Existe alguma razão mais plausível que outra para eleger uma teoria que não seja o convencimento subjetivo do cientista?" ${ }^{10}$ Com certeza, a forma e a essência, saltar-se-ia como de uma posição ética, porque os discursos assentar-se-iam no terreno da política $^{11}$. E, a formulação de teorias, o que tudo indicaria, não ultrapassaria a tênue proposta de ser uma opção útil e funcional que o legislador queria emprestá-la ${ }^{12}$.

Por isso, acredita-se que a doutrina possa ser uma fonte (REALE, 1994, p. 11-12) ${ }^{13}$, não indireta, mas direta na formação e criação do direito. Assim, pugna-se pelo uso da doutrina na estruturação da natureza jurídica, com isto marca a doutrina como a estruturação positiva do direito. Wald, in Rapport Brésilien (apud BERGER, 2001, p. 78), demonstra a importância da doutrina na formação do direito pátrio e comparado, que no Brasil e em Portugal, a sentença somente modificaria as regras escritas quando

\footnotetext{
9 Adiante, perceber-se-á que a elasticidade desta moldura normativa se rompe, motivo pelo qual há possibilidades de preenchimento diverso do que estatuído.

${ }^{10}$ Traduz-se os termos convencimento subjetivo do cientista como: interesse político.

${ }^{11}$ In: Barroso (2002, p. 69-70): "É bem verdade que, em sentido amplo, o Direito como um todo é político, porque suas fontes materiais se ordenam em função de relações de poder. Mas não está em análise o poder social, difusa e atomizadamente presente em qualquer agrupamento humano. Cuida-se, aqui, de uma modalidade específica, o poder político, como emanação da soberania do Estado. Este poder político singulariza-se por sua amplitude, incidindo sobre todas as pessoas e bens de um determinado território; por usa função, que é a de subordinar os interesses particulares ao interesse geral; é pelos meios de que se pode valer, notadamente a coação". Também, Luiz Sanchez Agesta (apud BARROSO, 2002, p. 53): "não é difícil intuir a enorme complexidade do enquadramento jurídico das relações, freqüentemente conflituosas, entre os indivíduos e um poder assim abrangente". Pergunta o autor: "é possível reduzir a realidade política a esquemas jurídicos?".

${ }^{12}$ Bergel (2001, p. 76) diz: “[...] Existe uma comunidade jurídica que, para além de suas diferenças internas, colabora para a criação, para a aplicação, e a evolução do direito e em cujo seio se exercem influências recíprocas. Não se pode, para estudar a criação do direito, desconhecer essas interações entre as diversas fontes do direito. Expressam-se em ações de umas sobre as outras ou em reações de umas contra as outras e procedem, conforme os casos, de um diálogo ou de um duelo entre os autores, os juízes, o legislador, os atores da vida jurídica. A regra de direito, a 'lei' no sentido mais lato desse termo, não é somente a do legislador: é em muitos aspectos 'a lei dos doutores', 'a lei dos juízes', 'a lei dos atores'”.

${ }^{13}$ Abandona-se este posicionamento de Reale, mas confira o que este diz: “[...] a doutrina, ao contrário do que sustentam alguns, não é fonte do direito, uma vez que as posições teóricas, por maior que seja a força cultural de seus expositores, não dispõem de per si do poder de obrigar. É a razão pela qual, [...] a doutrina não gera modelos jurídicos".
}

Nucleus, v.9, n.1, abr.2012 
há a esse respeito uma concordância da comunidade jurídica que abrange os juízes, os professores e os advogados. Em França, o "costume de origem erudita", marcaria a importância positiva da doutrina.

Assim, quando disseca a matéria, Berger (2001, p. 79) elucidaria, justificando a necessidade da doutrina para explicar, detalhar, sistematizar este mundo de "super-regulamentação", em que a multiplicidade dos textos, a desordem de uma regulamentação detalhada e minuciosa, tanto pelas contrariedades e ambiguidades, teria, portanto, a doutrina a função de redescobrir os princípios, restaurar os métodos de interpretação da lei, reconstruir métodos de raciocínio, etc., tal papel seria da doutrina.

$\mathrm{Na}$ análise da natureza jurídica proposta neste trabalho, pode-se destacar uma natureza propriamente jurídica e uma natureza anterior a própria judicialidade/normatividade. A análise, de uma natureza na lei, e de uma natureza na estrutura informativa da fonte que irá formar (formular) o direito, $i$. e., buscar a experiência antes de se estabelecer proposições já assentes para que possa, assim, observar o real, é a própria análise da natureza estrutural, mas não se pode reduzir à apenas esta investigação, devese ater ao que está positivado. Neste sentido Elías Díaz (apud AZEVEDO, 1989, p. 30-31) realça que há circunstâncias de que os elementos do raciocínio jurídico requerem análise global do meio social e dos interesses propriamente envolvidos, também tal raciocínio possa surtir efeitos na positividade do direito, in verbis:

Recusando-se a circunscrever a tarefa do jurista e da Dogmática Jurídica à análise
lógico-formal das normas, porquanto toda a atividade teórico-prática de um e de outra
"centra-se em um trabalho de investigação orientado no sentido da aplicação de uma
normatividade positiva, buscando dar solução a determinados problemas e conflitos que
podem surgir em uma sociedade", pode Elías Díaz conceber a Ciência do Direito como
ciência social. É que, se o direito "é para o jurista algo que lhe vem dado, positum,
posto..., tão somente em certa medida se encontra feito". A sociedade e o poder
legislativo são os criadores do direito. Colaborando com estes, a função própria do
jurista revela-se na determinação do significado do direito, a fim de aplicá-lo
corretamente à realidade social. E "essa aplicação-realização do direito... é algo
profundamente diverso de um simples trabalho mecânico de repetiçãa do que é dado na
legislação".

Desta forma, a análise da natureza estrutural é descritiva, em um momento anterior de considerar o que vem a ser a natureza jurídica do Droit D'Auteur.

Força-se a revelar, sem pretender um argumento de autoridade, os autores dogmáticos não expõem de onde buscam suas opiniões para formular os conceitos.

Base desta indagação é o posicionamento de Azevedo, acima. Cita-se, a maioria dos autores pesquisados para assim demonstrar que pugnam pela observação na lei e na doutrina, com certa prudência, a comprovar o que se afirma, e revelar a ficção ora criada, a surgir dicotomia entre direitos morais e patrimoniais a serem examinados no campo legislativo e doutrinário, por tal razão, não se pode resumir de forma singela os direitos de autor à modalidade de propriedade, mas sem dúvida é espécie desta e muito mais. O posicionamento de Monteiro (1963, p. 228, v. 3), no sentido que a natureza jurídica é controvertida na doutrina e que a censura do legislador em inserir a matéria no Direito das Coisas a propriedade literária, científica e artística, nesta concepção clássica, não se estende além dos bens corpóreos, não abrangendo o Direito das Coisas a propriedade intelectual, de natureza imaterial.

Leymann (apud BEVILAQUA, 1980, p. 1115; cf.: SILVA FILHO, 2002, p. 11) dizia que “[...] o direito autoral é, na sua essência e na sua origem, um direito ligado à pessoa do autor, a que se adiciona um prazo para depois de sua obra", o próprio projetista do Código Civil de 1916 trataria o direito autoral como propriedade imaterial, assim, traçando sua base legal, entre o domínio e os direitos reais sobre a coisa alheia, e "isto, porém, não significa desconhecer que haja neste direito, além de um aspecto geral outro pessoal, que se não desprende da própria personalidade do autor", salientaria Bevilaqua. Santos 
(1997, p. 403, v. 8) consideraria este direito com natureza controvertida, mas que o Código concebeu como propriedade sui generis, daí a contestação necessária: direito autoral em face da nova lei e a compatibilidade da concepção do domínio com a noção de propriedade resolúvel.

Bittar (2004, p. 11) com cautela ventila que os direitos autorais não se cingiriam nem a categoria dos direitos reais (revestidos apenas dos direitos denominados patrimoniais) e nem o direito das pessoas (em que se alojam os direitos morais), pois bipartiriam os dois citados feixes de direitos, não poderiam os direitos autorais se enquadrar nesta ou naquela categoria, sendo nova modalidade de direitos privados, teria natureza e finalidade intimamente ligados, em conjunto incindível. Seriam direitos de cunho intelectual, a realizar a defesa dos vínculos, tanto pessoais, quanto patrimoniais do autor e sua obra, com índole especial, sui generis, justificando uma regulamentação específica.

Denis Borges Barbosa (apud LEITE, 2004, p. 171) contribui à concepção de que o Direito de Autor teria uma natureza legislativa, na íntegra:

Um dos mais interessantes efeitos da doutrina do market failure é evidenciar a natureza primária da intervenção do Estado na proteção da propriedade intelectual. Deixado à liberdade do mercado, o investimento na criação do bem intelectual seria imediatamente dissipado pela liberdade de cópia. As forças livres do mercado fariam com que a competição - e os mais aptos nela - absorvessem imediatamente as inovações e as novas obras intelectuais. Assim é que a intervenção é necessária - restringindo as forças livres da concorrência - e criando restrições legais a tais forças. Pois que a criação da propriedade intelectual é - completa e exclusivamente - uma elaboração da lei, que não resulta de qualquer direito imanente, anterior à tal legislação [...].

Pugna o autor pela lei, enquanto necessitaria da segurança e coação estatal à garantir o direito patrimonial do autor, protegendo seu monopólio (ou direito de exclusivo) frente à liberdade (ou expropriação) do usuário (ou copista) de utilizar sua obra.

Necessário também observar que o protecionismo doutrinário emprestado à função mercadológica já se encontra notável no âmbito estadunidense. Os propósitos de proteção ao mercado norte-americano, com seu discurso protecionista e desigual, requereriam uma observação especial. Pelo simples fato de instaurar-se, teoricamente, área de livre comércio: deixaria esta doutrina e esta intervenção "primária" do Estado obra "desprotegida" no mercado? Creia-se que a negativa impera. A própria lei mercadológica, empresarial, restringe a atuação do particular na sua esfera. Não é pelo simples fato protetivo da intervenção do Estado ou não pelo fator determinante para tal restrição. A esfera privada de atuação tem suas próprias leis. No mundo atual, o Estado ficou restrito apenas à defesa da ordem pública - comumente chamado de Estado Mínimo (cf.: BORGES, [s.n.], p. 10).

\subsection{NATUREZA JURÍDICA PROPRIAMENTE DITA}

As citações preliminares merecem atenção, pois são colocações e enquadramentos de ordem geral, a refletir de forma introdutória que se faz, agora, mais especificadamente. A posição do direito pátrio quanto à natureza estrutural do Direito de Autor seria com base no dualismo moderado ou formal, doutrina do direito misto ou complexo de natureza dúplice, e que tal posição foi influenciada por Chaves e Duval, como quer Maria (1998, p. 24, v. 7).

A investigação requer uma partida, propondo-se que esta seja a teoria da natureza dupla de um direito misto e complexo, oferecendo, as seguintes premissas: a) do neodualismo; $b$ ) objeto imaterial específico; $c$ ) a natureza dúplice e justaposta; e, $c$ ) maior valia do direito moral do autor. 
Coloca-se as posições ${ }^{14}, a$ ) a favor: não se opõe ao elemento moral da paternidade intelectual e sua primazia, $b$ ) elemento patrimonial insuficiente a sua justificada configuração. Este aspecto pecuniário teria como aporte ideal, o entrelaçamento da teoria de Caselli + Otto Lenghi + Manzini.

Com o retrospecto da teoria, tem-se: a) Otto Lenghi: monista, patrimonial mitigada, direito real de usufruto; $b$ ) Manzini: monista, negativista da propriedade coletiva, recusou qualquer direito real; e, c) Caselli: conciliatória de direito subjetivo especial de notória complexidade: as faculdades com preponderância e um relevo maior sobre o elemento moral, a favorecer sempre um direito moral do autor $^{15}$. Em Caselli, a teoria se chama teoria da personalidade pensante. Assim, a análise estrutural, antes da concepção legal, vem a contribuir para os motivos determinantes responsáveis para a fonte da natureza jurídica do Direito de Autor. Contudo, a análise de como irá comportar o citado aporte ideal, seria a subsunção da legislação autoral nos institutos próprios que a LDA - Lei n. 9.610/98, lei que dispõe sobre os direitos autorais - (e a Constituição Federal de 1988) contém, nas realizações fáticas. Assim, tem-se que as premissas estão já assentes ( $a$ priori), mas antes foram determinadas por uma estrutura que as formou, positivando-as.

O comportamento fático será apenas para o enquadramento na legislação face ao determinado nesta, por aquela estrutura que a informou, a prevalecer um movimento instável, pendular, dinâmico neste comportamento $^{16}$. A perguntar: qual o conteúdo de comando que está no bojo da norma de conteúdo do Droit D'Auteur? Ora, volta-se ao aspecto formulado da estrutura ideal!

\subsection{COMPORTAMENTO DA NATUREZA JURÍDICA NO EXCLUSIVO}

Ascensão (2002) estruturou sua obra Direito autoral calcada neste direito de exclusivo e, assim, suas manifestações tem sido um discurso neste direito de exclusivo, ou seja, no seu contrário, exaltando a liberdade mitigada, ou o exclusivo prevalente. O exclusivo é, para o autor, de um modo geral, necessário, tanto no seu aspecto moral, quanto no pecuniário, patrimonial. A exploração econômica da obra também passa a ser do autor, e pode ele negociá-la.

Portanto, a restrição pelo social é a gratificação e merecimento do autor pela sua contribuição àquele pelo fato deste ter desenvolvido alguma obra que, temporariamente, irá satisfazer a ele e, posteriormente, a comunicação social, em definitivo.

Formula-se o seguinte exemplo como o direito de exclusivo absoluto para elucidar: caso alguém, a dirigir um carro, assoviar a música Smoke on the water do Deep Purple, pagaria direitos autorais pelo

\footnotetext{
${ }^{14}$ In: Bergel (2001, p. 21) tem-se a justificativa metodológica legitimadora, confira: "Se as diversas escolas de pensamento nutrem em si mesmas seus próprios excessos e não chegam, consideradas isoladamente, a uma definição completa e satisfatória do direito, esta só pode proceder de uma certa conjunção das teorias em questão, cuja apreciação depende das finalidades que reconhecemos no direito. Existe, para além das posições extremas, uma abordagem intermediária, que repousa na busca das finalidades alternativas e concilia as respectivas contribuições das diversas doutrinas ao mesmo tempo que as purga de seus excessos partidaristas [F. OST e M. VAN de KERCHOVE, Jalons pour une théorie critique du droit. Travaux et recherches]".

${ }^{15}$ A inferência que se faz deste posicionamento é o enquadramento na moldura do inciso XXVII do art. $5^{\circ}$ da CF/88.

${ }^{16}$ Tem-se este pensamento, em uma filosofia positivista de Auguste Comte, seu apoio (BERGEL, 2001, p. 20-21). Cf.: "Segundo ele, o indivíduo e a humanidade, em sua evolução intelectual e social, passam sucessivamente por uma fase teológica e militar, depois metafísica e legista, para atingir enfim a fase positiva e industrial, em que os homens se contentam em descobrir as leis efetivas que regem os fatos mediante a observação e o raciocínio. As sociedades e o Estado têm então 'o amor pelo princípio, a ordem por base e o progresso por objetivo'. O direito pode, assim, ser objeto de uma ciência positiva, pois procede essencialmente dos fenômenos sociais submetidos ao determinismo." E continua: "O positivismo sociológico é a concepção segundo a qual o direito se reduz ao direito positivo, tal como ele existe em dado momento e em dado território, extraindo-se a regra de direito da análise dos fatos sociais. Essa análise tem o mérito de lançar luzes na relatividade do direito no tempo e no espaço assim com a influência dos fatos sociais. Mas tem o inconveniente de limitar o direito a um reflexo servil dos fatos, mesmo dos mais condenáveis, ao passo que ele também pode domina-los, e de consagrar um determinismo inquietante e em geral inexato quando a vontade humana pode impor suas escolhas." Para um contraste, em Perelman (BERGEL, 2001, p. 22) no seu Logique juridique Nouvelle réthorique, in verbis: "O raciocínio jurídico não se reduz a uma mera dedução formal e lógica, mas é um constante confronto entre o valor de uma solução e sua coerência com o sistema jurídico.” Deve-se observar o que foi dito em Azevedo (1989, p. 30-1)
} 
simples fato de estar assoviando esta belíssima música! Ao passo que uma liberdade absoluta haveria a manifestação nos dois aspectos: patrimonial e moral. Seria esta música de todos, sem autoria determinada, qualquer do povo podendo adjudicar esta autoria e, no patrimonial, seria inexistente, pois.

Transporta-se esta lógica para outros institutos e formas de utilização, mas com o fundo a emanar o direito de exclusivo.

Barbosa (apud LEITE, 2004, p. 171) cita a liberdade como fator limitador do direito de exclusivo, que tanto exalta Ascensão. Concluir-se-ia que em Barbosa o Droit D'Auteur emanaria da lei, como direito de exclusivo, para proteger os Direitos do Autor, pois do contrário, a situação no meio natural, dissiparia este direito.

Já Ascensão (2002, p. 40), sobre a internet - sociedade da informação -, diz que o espaço para a atuação do social seria cerceado, gradativamente. Haveria um aumento do direito de exclusivo ou monopólio, in verbis:

Nos Estados Unidos da América, porque o lugar prioritário que ocupam nas industrias de copyright explica que se procure uma protecção sempre acrescida para as suas exportações. Na Europa, porque a integração é económica, é um mercado comum: os mercadores querem sempre aumentar os seus proventos e a cultura ou o interesse público reduzem-se a uma espécie de fundo musical para os discursos oficiais.

De facto, o cidadão comum defronta-se crescentemente com o arame farpado. Há cada dia mais zonas cuja entrada está proibida ou reservada. Com isso, o diálogo social perde fluidez. A nossa liberdade passa a ser uma liberdade condicionada: o que fazemos ou podemos depende cada vez menos da nossa espontaneidade e cada vez mais daqueles que se asseguraram posições de privilégio no espaço social.

Em Barbosa, ele reivindica a necessidade de se restringir a atuação do mercado, a proteger as obras dos copistas devoradores. E em Ascensão, comenta que a limitação da liberdade de utilizar a obra por parte dos cidadãos é restrita. Em ambos operam-se interesses distintos para um mesmo instituto. No primeiro, tem-se uma obrigação de não fazer, se utilizado os direitos obrigacionais; e, no segundo, uma obrigação de fazer. Mas, ambos, tratam de forma não privatística. O que aludem uma proteção estatal de tal ramo do direito. Desta forma, complexo é justificar a natureza jurídica do direito de autor neste direito de exclusivo, seja uma natureza que se propaga no interesse econômico ${ }^{17}$ ora no aspecto patrimonial, com Barbosa, ora no aspecto cultural, com Ascensão.

Ademais, com todo o aparato estrutural citado, encontra-se, uma doutrina nos EUA, o que parece ser uma exceção ao Direito de Autor - concebendo este como direito de exclusivo -, denominada de fair use, com a justificativa de tornar legítimo o uso de obras literárias através da internet, desde que sem intuito de lucro, sem intenções comerciais, obedecendo a certos requisitos (BLUM; ABRUSIO, 2004, p. 253).

O fundamento tem o princípio da vinculação - puramente um caráter informativo - a corresponder com a finalidade social, a convergir com a proposta inicial da internet quando aberta à comunidade global,

\footnotetext{
${ }^{17}$ Bergel (2001, p. 19), sobre o caráter econômico do direito, cf.: Com o inglês Bentham, início do séc. XIX, o direito procede da economia: "[...] a arte jurídica é anexada à economia política, sob a ditadura do útil." Somente com Karl Marx e Engels que o fator econômico é considerado com saliência na produção do direito. "O direito positivo mostra-se neles 'a expressão dos interesses econômicos da classe dominante', dos capitalistas nas sociedades burguesas e do proletariado quando ele estabelece sua ditadura. O direito é então a 'superestrutura' da realidade econômica ligada à evolução das relações de produção e o instrumento de coerção da classe dirigente. Essa coerção é necessária para garantir a ditadura do proletariado; mas, depois de uma fase transitória em cujo curso devem abolir-se as oposições de interesses e transformar-se as mentalidades, o direito deve desaparecer ao mesmo tempo que o aparelho de coerção do Estado. Partindo do "materialismo histórico' segundo o qual o direito procede da economia e se explica por relações de força, Marx prevê sua evolução que termina com seu desaparecimento.” Ainda, sobre o caráter econômico do direito, cf.: Correas (1995, p. 269). Sobre o direito privado, in verbis: "A idéia era, então, que o direito privado 'se refere' à circulação mercantil, a quem protege facilitando sua reprodução." Anota-se o seguinte procedimento para este tipo de análise: "O modelo está constituído pela descrição marxiana da circulação mercantil, cujos elementos centrais, são, como se sabe, e simplificando muito, as mercadorias que se intercambiam conforme seu valor e os portadores das mesmas."
}

Nucleus, v.9, n.1, abr.2012 
e não uma violação dos Direitos de Autor. Este instituto do fair use não foi recepcionado pela legislação pátria, mas o Superior Tribunal de Justiça - STJ tem manifestado que nos shows oferecidos subvencionados - pela municipalidade, quando não cobrado ingresso não há ofensa aos direitos autorais, pode-se chamar de um atípico fair use brasileiro. Neste diapasão: Relator Ministro Carlos Alberto Menezes Direito, da Terceira Turma, REsp 123.067-SP, n. 1997/0017288-0, data do julgamento, 03.03.1998, data da publicação/fonte: DJ 18.05.1998, p. 83 e RSTJ vol. 110, p. $237^{18}$. Deste modo, a liberdade da comunidade e a cultura, patrocinada pelo Poder Público, utilizar-se-iam da obra como um expropriador - a ferir, segundo a legislação, o direito de autor, mas não acatada pelo julgado mencionado.

Sob enfoque constitucional da matéria, diz a Constituição Federal de 1988, art. 5, XXVII: "aos autores pertence o direito exclusivo de utilização, publicação ou reprodução de suas obras, transmissível aos herdeiros pelo tempo que a lei fixar”. Fomenta-se com uma interpretação constitucional neste julgado, o que daria margem a indagar supressão de instância, pois matéria de ordem constitucional é de competência exclusiva do Supremo Tribunal Federal - análise em controle difuso não supriria. Mas, nada impede que a interpretação seja a atender o princípio da proporcionalidade. As melhores interpretações são aquelas que sacrificam o mínimo para preservar o máximo de direitos fundamentais. Desse modo, Freitas (2002, p. 194) entende que o princípio da proporcionalidade é muito mais que a adequação entre meio/fim, é sacrificar o mínimo para preservar o máximo de direitos fundamentais: "Em nenhuma circunstância um direito de estatura constitucional deve suprimir, por inteiro, outro direito de mesma estatura".

Deste modo, a utilização feita, sem o consentimento do autor, deveria indenizar este, como dispõe a LDA, arts. 102 usque 110 (Título VII, Das Sanções às Violações dos Direitos Autorais).

No tocante à utilização (Título IV, Da Utilização de Obras Intelectuais e dos Fonogramas, Capítulo II, da Comunicação ao Público) a LDA no seu art. 68, apresenta as condições desta utilização não ser ofensiva aos Direitos do Autor. Onde diz que sem prévia e expressa autorização não podem ser utilizadas as obras.

Outro ponto debatido no julgado é a subvenção pelo Poder Público, e, novamente, contrária à legislação e lesivo ao direito de exclusivo do autor, conforme quer a LDA (Título I, Disposições Preliminares), art. $6^{\circ}$, in verbis: "não serão de domínio da União, dos Estados, do Distrito Federal ou dos Municípios as obras por eles simplesmente subvencionadas".

Mas, por outro lado, o Estado agiu em prol da cultura e do interesse social, conforme se encontra ao analisar o julgado. De outra sorte também, esta desapropriação da obra do autor, particular, meio privado, faz do Estado, interventor na álea econômica intervindo no campo regulado pelo direito privado, a invadir a esfera privatística de titularidade do setor privado e do empresário comum ${ }^{19-20}$.

Contudo, esta desapropriação, mesmo que temporária, de cunho subvencionista, não deixa de ter base no interesse social. Pedro Calmon (apud CRETELLA JÚNIOR, 1972, p. 51-52, v. 9) retrata com maestria, sobre o instituto da desapropriação, de uma forma geral, in verbis:

\footnotetext{
18 Ementa: DIREITO AUTORAL. ESPETACULO REALIZADO NA RUA, COM SUBVENÇÃO DA PREFEITURA MUNICIPAL, INTEIRAMENTE GRATUITO, EM BENEFICIO DA COMUNIDADE. 1. NA LINHA DOS PRECEDENTES DA CORTE, O PAGAMENTO DOS DIREITOS AUTORAIS CABE QUANDO HOUVER QUALQUER TIPO DE PROVEITO, O QUE NÃO OCORRE NAQUELES CASOS NOS QUAIS NÃO HA COBRANÇA DE INGRESSO, NÃO HÁ PAGAMENTO AOS ARTISTAS, O ESPETACULO E REALIZADO NAS RUAS E A PARTICIPAÇÃO DO ENTE MUNICIPAL LIMITA-SE A UMA DETERMINADA SUBVENÇÃO AS ESCOLAS DE SAMBA QUE, EFETIVAMENTE RESPONDEM PELO ESPETACULO. TRATA-SE, NESTE CASO, DA PARTICIPAÇÃO GOVERNAMENTAL EM PROGRAMA DE DESENVOLVIMENTO DA CULTURA POPULAR EM EXCLUSIVO PROVEITO DA COMUNIDADE. 2. RECURSO ESPECIAL CONHECIDO, MAS IMPROVIDO. ACÓRDÃO: POR UNANIMIDADE, CONHECER DO RECURSO ESPECIAL, MAS NEGAR-LHE PROVIMENTO.

${ }^{19}$ Para uma leitura com maior propriedade e análise profunda, cf.: Borges ([s. n.], p. 10). Fornecido pelo próprio autor, em aula ministrada no curso de MBA-Empresarial da UNIFRAN, matéria de Direito Administrativo Econômico, dia 14.05.05.

${ }^{20}$ Estaria aí o Estado a se comportar como empresário?.
} 
[...] a desapropriação por interesse social é aquele que se promove para atender ao melhor uso da propriedade, ao seu rendimento em consonância com aquele interesse, à sua devida estimativa, em articulação com ele, ao bem comum que não pode ficar na dependência do egoísmo, que a despreza, ou da estupidez, que o contraria.

A desapropriação, [...] significa a incorporação para a distribuição, que se pressupõe equânime, e então melhor se denominará de justiça distributiva do Estado - tendo por escopo o interesse social, assim no seu primado sobre a esfera individualista da ação econômica. Este detalhe da dogmática constitucional é uma consulta ao coração do seu sistema.

Relembra-se o que foi dito antes por Barroso (2002, p. 69-70), onde a prevalência e a preferência do interesse geral frente ao interesse particular, sendo esta a função do Estado, mesmo esta função caracterizada pelo poder coativo estatal (cf.: KELSEN, 2000, p. 35-36).

Assim, não há decisão contra legem ${ }^{21}$ uma vez que o art. $5^{\circ}$ da LINDB - Lei de Introdução às Normas do Direito Brasileiro -, permite quando for contrário aos interesses sociais, in verbis: "Na aplicação da lei, o juiz atenderá aos fins sociais a que ela se dirige e às exigências do bem comum". Também, tem-se a necessidade do juiz aplicar o que é favorável ao social e atender os seus anseios, e não permanecer ao sectarismo normativo com a finalidade de satisfazer postulados burocráticos ou mesmo pugnar pela intenção da expressão pelo legislador. Deste modo, Azevedo (2000, p. 136) diz:

Para chegar a decisões adequadas e socialmente convincentes é indispensável superar o positivismo jurídico. Contudo, a superação deste e da ideologia que o anima não pode conduzir à negação do ordenamento jurídico mediante a tácita permissão de decidir o juiz as questões ao seu alvedrio. O problema põe-se justamente em função da existência da ordem jurídica. Se a subjetividade do juiz não pode ser afastada, por envolver a interpretação do direito sua pessoa por inteiro, não pode ele, no entanto, afastar-se do ordenamento jurídico em função de suas concepções pessoais. É entre dois extremos - a redução da aplicação do direito à formulação de um silogismo e o ponto de vista segundo o qual, parecendo ao juiz injusta a lei, poderia ele sponte sua negar-lhe cumprimento - que se deve realizar o processo hermenêutico e exercitar o poder criativo pelos diversos órgãos do Poder Judiciário.

Assim, é patente que os sectarismos positivos e impositivos não devem prevalecer ao social e ao interesse maior da lei, que é a satisfação dos interesses sociais.

Contudo, uma compreensão do social, dos anseios sociais frente à norma impositiva injusta, é capaz de efetivar a justiça onde tem aparência de justiça.

\section{CONCLUSÃO}

Assim, creia-se que o desenvolvimento do texto tenha sido favorável à elucidação do que venha a ser a criação da natureza jurídica do Direito de Autor, pois é extremamente complexo seu enquadramento e aceitação por parte da comunidade jurídica, mesmo a científica.

A contribuição quanto ao enquadramento do direito de autor é de que a posição do direito pátrio quanto à natureza estrutural do Direito de Autor seria com base no dualismo moderado ou formal, doutrina

\footnotetext{
${ }^{21}$ Cf.: sobre decisões contrárias às leis, Kelsen (2000, p. 289-290): "De todo modo, tem de aceitar-se como possível investiga-la a partir de outras fontes que não a expressão verbal da própria norma, na medida em que possa suprimir-se que esta não corresponde à vontade de quem estabeleceu a norma. Que a chamada vontade do legislador ou a intenção das partes que estipulam um negócio jurídico possam não corresponder às palavras que são expressas na lei ou no negócio jurídico, é uma possibilidade reconhecida, de modo inteiramente geral, pela jurisprudência tradicional. A discrepância entre vontade e expressão pode ser completa, mas também pode ser apenas parcial. Este último caso apresenta-se quando a vontade do legislador ou a intenção das partes correspondem pelo menos a uma das várias significações que a expressão verbal da norma veicula. A indeterminação do ato jurídico a pôr pode finalmente ser também a conseqüência do fato de duas normas, que pretendem valer simultaneamente porque, v.g., estão contidas numa e mesma lei -, contradizerem total ou parcialmente." Nota-se a preocupação linguísticosemiológico em Kelsen e, a possibilidade de decidir contra legem.
}

Nucleus, v.9, n.1, abr.2012 
do direito misto ou complexo de natureza dúplice, e que tal posição foi influenciada por Antonio Chaves e Hermano Duval, como quer Maria (1998, p. 24, v. 7). A investigação requereu uma partida, propondo-se a teoria da natureza dupla de um direito misto e complexo, oferecendo, as seguintes premissas: $a$ ) do neodualismo; $b$ ) objeto imaterial específico; $c$ ) a natureza dúplice e justaposta; e, $c$ ) maior valia do direito moral do autor. Coloca-se as posições, $a$ ) a favor: não se opõe ao elemento moral da paternidade intelectual e sua primazia, $b$ ) elemento patrimonial insuficiente a sua justificada configuração. Este aspecto pecuniário teria como aporte ideal, o entrelaçamento da teoria de Caselli + Otto Lenghi + Manzini.

Notou-se que, quando colocada a natureza jurídica do Direito de Autor frente ao social, houve a negativa de um direito, como descrito, mas atendeu, antes um interesse social que os anseios privados. Deve-se ressaltar que as estruturas teóricas e a História, mesmo a notar seu comportamento cíclico, são importantes para identificar a formação da natureza jurídica, seja de qual ramo do Direito for investigado.

Necessário é observar como se comporta esta natureza quando colocada na práxis, qual é o seu comportamento, qual a ideia que irá influenciar na construção do conceito e, o que é mais importante, qual o processo que será responsável para tal mudança frente ao real, concreto. Ou melhor, quando o direito se realiza no real, tem-se o seu conceito. Como diz Hegel (2003, p. 1), "é antes uma interação especulativa que um método formal”.

Portanto, propôs-se, como o direito de exclusivo, realizar uma investigação, antes compreensiva que crítica, de como teria o comportamento deste importantíssimo instituto ao Direito de Autor. Várias foram as pinceladas de filosofia e método para se chegar à demonstração que tal instituto não se comportou como o previsto na LDA quando posto na realidade. Reitera-se que é necessário mesclar as fontes do direito para uma melhor compreensão e formação, pois quando se utiliza o posicionamento de Comte e de Elías Díaz, tentou-se conciliar correntes, a colocar o que há de prevalente e não contraditório, em cada uma delas, compreendendo-as.

Assim, Clóvis da Silva Monteiro (2006) disse que "a crítica é uma surpresa” aqui, encara-se como necessária, visto a necessidade de uma maior literatura carecida nesta empreitada e, não obstante, um desenvolvimento condensado e sintético do objeto.

A ordem jurídica em vigor de um país não é o sistema que está em vigor, mas aquelas que buscam melhorar a vida seja através da interpretação pelos juízes, promotores advogados, professores, alunos de direito (COELHO, 2004, p. 397).

\section{REFERÊNCIAS ${ }^{22}$}

ARAÚJO, V.N. de. Fundamentos aristotélicos do direito natural. Porto Alegre, Serio Antonio Fabris Editor, 1988.

ASCENSÃO, J. de O. Direito autoral. 2. ed. Rio de Janeiro: Renovar, 1997.

Direito intelectual, exclusivo e liberdade. Revista da ABPI - Associação Brasileira da Propriedade Intelectual. São Paulo, nº 54, jul. ago. de 2002.

AZEVEDO, P. F. de. Aplicação do direito e contexto social. 2. ed. São Paulo: Revista dos Tribunais, 2000 . 
$\overline{1989 .}$

Crítica à dogmática e hermenêutica jurídica. Porto Alegre: Sergio Antonio Fabris Editor,

BARROSO, L. R.. O direito constitucional e a efetividade de suas normas: limites e possibilidades da constituição brasileira. 6. ed. Rio de Janeiro: Renovar, 2002.

BERGEL, J.-L.. Teoria geral do direito. Tradução de Maria Ermantina Galvão. São Paulo: Martins Fontes, 2001.

BETIOLI, A. B.. Introdução ao direito. 8. ed. São Paulo: Letras e Letras, 2002.

BEVILAQUA, C.. Teoria geral do direito civil. 2. ed. Rio de Janeiro: Rio, 1980.

BITTAR, C. A.. Direito de autor. 2. ed. Rio de Janeiro: Forense Universitária, 1994.

Direito de autor. 4. ed. Rio de Janeiro: Forense Universitária, 2004.

Direitos reais. Rio de Janeiro: Forense Universitária, 1991.

BOBBIO, N.. Teoria do ordenamento jurídico. Tradução de Maria Celeste Cordeiro Leite dos Santos. 10. ed. Brasília: Universidade Brasília, 1999.

BORGES, A. W.. A ordem econômica e financeira da Constituição e os monopólios. [s. n.].

CRETELLA JÚNIOR, J.. Tratado de direito administrativo: desapropriação no direito brasileiro. Rio de Janeiro: Forense, 1972. v. 9.

CHAVES, A.. Lições de direito civil: direito das coisas. São Paulo: Revista dos Tribunais, 1974. v. 1.

COELHO, L. F.. Aulas de introdução ao direito. Barueri: Malone, 2004.

CORREAS, ÓSCAR. Crítica da ideologia jurídica: ensaio sócio-semiológico. Tradução de Roberto Bueno. Porto Alegre: Sérgio Antonio Fabris Editor, 1995.

FRANÇA, R. L.. (Coord.). Enciclopédia Saraiva do Direito. São Paulo: Saraiva, 1978, p. 269-302. v. 9.

FREITAS, J.. A interpretação sistemática do direito. 3. ed. São Paulo: Malheiros, 2002.

GOMES, O.. Introdução ao direito civil. 18. ed. Rio de Janeiro: Forense, 2001.

HEGEL, G.W. F.. Princípios da filosofia do direito. Tradução de Orlando Vitorino. São Paulo: Martins Fontes, 2003.

KANT, E.. Doutrina do direito. Tradução de Edson Bini. 2. ed. São Paulo: Ícone, 1993.

KELSEN, H.. Teoria pura do direito. Tradução de João Baptista Machado. 6. ed. São Paulo: Martins Fontes, 2000.

LEITE, E. L.. Direito de autor. Brasília: Brasília Jurídica, 2004.

MARIA, J. S. de S.. Curso de direito civil: direitos reais limitados. Rio de Janeiro: Freitas Bastos, 1998.v. 7.

MARTINS FILHO, I. G. da S.. A legitimidade do direito positivo: direito natural, democracia e jurisprudência. Rio de Janeiro: Forense Universitária, 1992. p. 56.

Nucleus, v.9, n.1, abr.2012 
MELLO, C. A. B. de. Conteúdo jurídico do princípio da igualdade. 3. ed. São Paulo: Malheiros, 2004.

MELLO, M. B. de. Teoria do fato jurídico: plano da eficácia. 2. ed. São Paulo: Saraiva, 2005.

MICHAELIS 2000: moderno dicionário da língua portuguesa. Rio de Janeiro: Reader's digest; São Paulo: Melhoramentos, 2000. v. 2.

MILEO, B. A. P.; SOARES, G. A.. A cultura tradicional e o direito autoral. Revista da ABPI Associação Brasileira da Propriedade Intelectual. São Paulo, nº 76, mai. jun. de 2005.

MIRANDA, P. de. Tratado de direito privado. Campinas: Bookseller, 2002. v. 26.

MONTEIRO, C. da S.. Ligação da pirataria com o narcotráfico; falta de polícia; necessidade de uniformizar a legislação; as principais vítimas deste crime. Fonte:

http://www2.camara.gov.br/internet/tv/chamadaExterna.html?link=http://www.camara.gov.br/internet/tvc amara/default.asp?selecao=MATAGRUPADA, acesso: 29.04.06.

MONTEIRO, W. de B.. Curso de direito civil: parte geral. 5. ed. São Paulo: Saraiva, 1963. v. 1 e 3.

Curso de direito civil: direito das coisas. 5. ed. São Paulo: Saraiva, 1963. v. 3.

Curso de direito civil: direito das obrigações. 5. ed. São Paulo: Saraiva, 1963. v. 4.

O ESTAdO DE SÃO PAULO. Caderno Economia \& Negócios, dia 7 de maio de 2006, B16.

OPICE BLUM, R. M. S.; ABRUSIO, J. . Direito autoral eletrônico. p. 247-59. Revista Jurídica Unicoc. Ano 1, v. 1, n. 1, jun. 2004. ISSN 1806-7603.

REALE, M.. Fontes e modelo do direito: para um novo paradigma hermenêutico. São Paulo: Saraiva, 1994.

RIPERT, G.. Aspectos jurídicos do capitalismo moderno. Campinas: Red Livros, 2002.

ROUBIER, P.. Droits subjectifs et situations juridiques. Paris: Dalloz, 1963.

SILVA FILHO, A. M. da. Conteúdo dos direitos do autor. Revista dos Tribunais. São Paulo, ano 91, v. 806, p. 11-27, dez. 2002.

SANTOS, J. M. de C.. Código civil brasileiro interpretado: direito das coisas. 12. ed. Rio de Janeiro: Freitas Bastos, 1977. v. 8.

STRECK, L. L.. Hermenêutica jurídica e(m) crise: uma exploração hermenêutica da construção do direito. 4. ed. Porto Alegre: Livraria do Advogado, 2003.

VENOSA, S. de S.. Direito civil: teoria geral das obrigações e teoria geral dos contratos. 3. ed. São Paulo: Atlas, 2003. v. 2. 
